\title{
Study for analyzing world judo player's technical type and time
}

\author{
Tae-whan Kim \& Seung-hun Lee* \\ Korea Institute of Sport Science
}

\begin{abstract}
[Purpose] Based on the match data of major judo world competitions in the last five years, this study identifies differences in general characteristics and environmental factors according to scoring technique and scoring times. And by exploring the factors associated with scoring technique, I would like to present a practical strategy that can be used to establish guided tactics. [Methods] 50,828 points were used for analysis of the entire men and women who competed from 2016 to 2020. Differences in the characteristics of the world's leading athletes according to their types of technique were used in conjunction with the chi-square test and the one-way ANOVA with Sceffe test to produce results. [Results] The results of this study showed that the type of skill by foot technique was the most common, and the ratio of hand skill to female player to push and foot skill was relatively high. The higher the weight class, the lower the ratio of hand technique, the higher the press rate, and the frequency of skill types also increased. At the Olympic Games, the ratio of hardening technique was higher than that of other competitions, and as the year progressed, the ratio of hand and waist technique increased, and the number of mat-hold decreased. The ratio of hardening technology was relatively high, and the ratio of hand-to-foot technology was relatively high as the semi-final and final rounds were higher. As for technical time, the male athlete's skill time appeared to be about 12 seconds longer on average, with the lowest in the heavyweight class and the longest in the lightweight class. Athletes from the Asian continent appeared to have the longest technical time, which is believed to have resulted from the characteristics of excellent physical strength, good endurance, and strong hardening technique. The skill time leading to the score by pressing and hand skill was the longest, and the waist skill and grip skill time were relatively short. Half of them appeared about 5 seconds shorter on average compared to the first round, and the more important the game (the 4th round, semi-final, and final) the longer the skill time. [Conclusion] In conclusion, through this study, the characteristics of the world judo players' skill types and time were confirmed, and based on this, it is necessary to analyze and systematize the technical types of the world's best athletes, including Korean athletes, in order to improve their judo performance.
\end{abstract}

Key words: Judo, Elite Athletes, Sports Competition analysis, Performance Analysis, Sports Big Data

\section{서 론}

논문 투고일 : 2020. 07. 02 .

논문 수정일 : 2020. 08. 17.

게재 확정일 : 2020. 08. 27.

* 교신저자 : 이승훈(shlee8283@gmail.com).
스포츠 경기를 과학적으로 분석하는 것은 선수나 팀의 경기력 향상과 함께 향후 훈련 계획을 수립하는데 많은 도움을 주고 있다. 특히 경기력을 향상시키기 위해서는 
객관적이고 체계적인 경기 내용에 대한 분석이 필요한데, 이러한 분석들은 경기력이나 승패에 영향을 주는 요인들 을 추출해 낼 수 있기 때문이다(Hughes \& Franks, 2004).

한국에서 유도는 투기종목 엘리트 스포츠로 명성이 높 다. 국제 대회에서 상위 입상 가능한 경기력을 갖춘 선수 들을 다수 보유하고 있고, 역대올림픽에서의 메달 획득 숫자 또한 많은 편에 속한다. 유도 종주국 일본과 프랑스 다음으로 금메달을 가장 많이 획득한 국가이며, 최상의 유도 실력을 자랑하는 유도 강국이기도 하다 $(\mathrm{Kim} \& \mathrm{Ha}$, 2010). 유도는 승패를 궁극적 목적으로 하는 무술이 아 니라 단련을 기초로 하여 심신의 수련과 인간 완성을 위 한 노력을 시도하는 무술이라 할 수 있다(Lee, 2010). 그 러나 현대 스포츠로서의 유도는 기술에 의한 공격과 수비 로 승패를 결정짓는 경기이며 다양한 기술을 사용하여 상 대 선수를 메치거나, 조르고, 관절을 ㄲㄲㄲ거나, 누르는 격투 경기이다(An, 2009). 또한 남녀 각 7개 체급으로 분류해 4 분이라는 한정된 시간 내에서 이루어지는 개인 경기임 과 동시에 상대를 대상으로 하는 대인 경기이기 때문에 시공간에 따른 기술 특성의 차이가 존재한다. 기술적인 측면에서의 유도 경기는 상대와 맞잡은 상태로 상대방의 움직임을 포착한 후 순간적으로 기술을 발휘하거나 상대 의 움직임에 신속하게 대응해야 하는 특성이 있다. 유도 기술에는 서서 행하는 메치기와 매트에 누워서 행하는 굳 히기로 나눌 수 있는데, 메치기 기술은 상대를 던지는 기 술로써, 서서 메치는 선기술(tachi-waza)과 누우면서 메 치는 누우며 메치기 (sutemi-waza) 기술로 분류된다. 선 기술에는 손 기술, 허리 기술, 발 기술이 있으며 누우며 메치기 기술에는 바로누우며메치기와 모로누우며메치기 로 나눌 수 있다. 굳히기 기술은 누르기, 조르기, 꺾기 기 술로 구분된다(Pereira et al., 2019; Brousse \& Matsumoto, 1999). 실제 경기에서 기술들을 효과적으 로 발휘하기 위해서는 고도의 기술 능력과 실제 경기에서 의 전술 능력이 요구 되는데(Kwon et al., 2002), 국제 대회에 많이 출전하는 엘리트선수들은 올림픽에 참가한 선수와 마찬가지로 체력과 기술, 전략 등 실전 훈련이 충 분한 선수들로 그 사용하는 기술과 능력은 거의 평준화되 었다고 할 수 있다. 따라서 유명한 국제 대회에 출전하는 선수라면 어느 나라에서 출전했느냐에 관계없이 그 개인
의 실력은 세계 최고 수준으로 평가되는 능력을 가지고 있다(Kim et al., 2010).

지금까지 유도 경기 분석은 시합에서의 효율성을 높이 고, 훈련을 향상시키기 위한 방법을 찾는 것에 중점을 두 고 이루어졌으며(Drid et al., 2013), 이를 바탕으로 기술 훈련 정보를 단순화해 학습을 강화하기 위한 스킬 획득 과 정의 일부로 활용할 수 있다(Calmet et al., 2010). 특히, 세계 우수 선수들의 주요 기술 빈도와 득점 시간을 살펴보 는 것은 유도 경기를 분석하는데 중요한 자료가 될 수 있 으며, 특정 기술의 분포와 유형을 통해 세부 기술의 패턴 분석에 전략적으로 활용할 수 있다. 유도선수의 경기력과 관련된 연구에서 Kang(2014)은 2012 런던올림픽 국가 대표 유도선수들을 대상으로 득점 기술을 분석하였는데, 남자 선수에 비해 여자 선수들은 다리기술(86.3\%)을 극 단적으로 사용하고 있는 것으로 보고하였다. 또한 기술의 사용 형태가 단조로운 경향을 보이고 있으며 연결 기술 사 용 빈도가 낮다고 지적했다. Lee \& Cho(2018)는 유도 세 계선수권대회 우수 여자 선수의 득점 기술의 차이를 비교 분석했는데 체급에 따른 득점 기술에는 차이가 없으며, 대 륙에 따른 득점 기술에는 통계적으로 유의한 차이가 있다 고 밝혔다. 하지만 입상한 소수의 선수를 대상으로 득점 기술을 분석하여 외적타당도 확보에 어려움이 있었으며, 시간의 흐름과 기술의 변화를 고려하지 않은 제한점을 보 고했다. 이와 같이 유도에서의 득점 기술 분석은 득점 기 술별, 유형별, 시간에 따라 결과에 직접적인 영향을 줄 수 있다. 한 경기에 평균 1,2 회 정도의 기술이 득점으로 연 결되는데 이는 곧 경기 결과와 연결되므로 이에 대해 정확 한 자료를 확보하는 것이 선수들이 기술의 다양성을 확보 하고 전략적으로 관리하는데 있어 주요한 요인이 될 수 있 다. 이를 위한 종합적이고 체계적인 득점 기술과 유형 분 석이 반드시 이뤄져야 할 필요가 있는데, 체계적인 기록. 분석을 위한 이론적, 기술적 발전은 스포츠 경기에 큰 비 중을 차지해가고 있다(Kim \& Choi, 2008). 최근까지 유 도 경기에 대한 기술 유형 분석은 소수의 자료를 바탕으로 단기적 유형을 파악하는데 그쳤고, 세계대회 기록을 통한 국제적 기술 동향 분석과 전반적인 기술 수행의 움직임, 변칙 기술 등의 다양한 변인에 대한 기술과 유형 변화를 살펴보고자 한 연구는 미비하다.

따라서 본 연구에서는 최근 5년간의 메이저급 유도 세 
계대회 기록을 바탕으로 세계대회 출전 선수들의 득점 기 술과 득점 시간에 따른 일반적 특성 및 환경적 요소에 대 한 차이를 파악하고 득점 기술과 관련된 요인을 탐색함으 로써 유도 전술 수립에 활용할 수 있는 실무적 전략을 제 시하고자 한다. 본 연구의 결과는 향후 엘리트 유도선수 들의 경기 전략 수립 자료로 활용될 수 있을 것이며, 올림 픽 및 세계대회에서의 전략 수립과 대응 방안을 위한 기 초 자료 제공에 목적을 두고자 한다.

\section{연구방법}

\section{연구대상}

본 연구는 인터넷 자료를 기반으로 국제유도연맹 (IJF: International judo federation)에서 제공하는 공 식 기록을 바탕으로 2016년에서 2020년까지 총 5년간 국제유도연맹 주관 대회인 그랑프리, 그랜드슬램, 마스 터즈, 세계선수권, 올림픽에 출전한 남녀 선수 전체를 모 집단으로 선정하였다. 한판 또는 절반으로 연결된 기술에 대한 전체 사례를 유층 표집(stratified sampling) 방법 을 이용하여 총 50,828 득점 기술을 분석에 이용하였다. 〈Table 1〉은 대회 및 연도별 득점 기술 빈도를 구분하여 정리한 표이다.

\section{자료수집과 측정변인}

국제유도연맹에서는 경기별 득점 기술정보를 공개하 고 있다. 본 연구의 자료 수집을 위하여 국제유도연맹 경 기 기록 및 기술 유형을 수집하였고 자료 중 결측치를 갖 는 자료는 제외하였다. 국제유도연맹에서 제공하는 기술 유형은 8가지로 손 기술, 허리 기술, 발 기술, 모로누우며 메치기, 바로누우며메치기, 누르기, 조르기, 꺾기로 구분 해서 제시하고 있다. 본 연구에서는 득점 기술 총 8 개의 자료를 수집하였고, 이에 대한 정의는 〈Table 2 〉와 같다. 국제유도연맹 대회는 남녀 7개 체급으로 구분되는데, 체 급별 기술 특징 및 시간을 분석하기 위해 Lee \& Choi(2018)의 선행연구에서 사용한 체급 분류를 〈Table 3)과 같이 남녀로 구분해서 제시했다.
Table 1. Characteristics of the subjects

(N)

\begin{tabular}{cccccc}
\hline \hline Events & 2016 & 2017 & 2018 & 2019 & 2020 \\
\hline $\begin{array}{c}\text { GP } \\
\mathrm{N}=24,233\end{array}$ & 3,509 & 4,317 & 7,708 & 7,659 & 1,040 \\
\hline $\begin{array}{c}\mathrm{GS} \\
\mathrm{N}=17,486\end{array}$ & 1,789 & 3,378 & 3,786 & 6,025 & 2,508 \\
\hline $\begin{array}{c}\mathrm{WC} \\
\mathrm{N}=6,588\end{array}$ & 0 & 2,654 & 2,321 & 1,613 & 0 \\
\hline $\begin{array}{c}\mathrm{MT} \\
\mathrm{N}=2,029\end{array}$ & 333 & 469 & 488 & 739 & 0 \\
\hline $\begin{array}{c}\text { OG } \\
\mathrm{N}=492\end{array}$ & 492 & 0 & 0 & 0 & 0 \\
\hline $\begin{array}{c}\text { Total } \\
\text { 6,123 }\end{array}$ & 10,818 & 14,303 & 16,036 & 3,548 \\
\hline \hline $\begin{array}{l}\text { GP } \\
\text { Championships MT: Masters }\end{array}$ & OG: Olympic Games &
\end{tabular}

Table 2. Contents and technical type variables

\begin{tabular}{ccc}
\hline \hline Variables & Technical type & Contents \\
\hline$V_{1}$ & Te-waza & Hand technique \\
\hline$V_{2}$ & Koshi-waza & Waist technique \\
\hline$V_{3}$ & Ashi-waza & Foot technique \\
\hline$V_{4}$ & Yoko-sutemi-waza & Straight throwing technique \\
\hline$V_{5}$ & Ma-sutemi-waza & Side throwing technique \\
\hline$V_{6}$ & Osaekomi-waza & Mat-hold technique \\
\hline$V_{7}$ & Shime-waza & Choking technique \\
\hline$V_{8}$ & Kansetsu-waza & Arm-bar technique \\
\hline \hline
\end{tabular}

Table 3. Weight class classification

\begin{tabular}{ccc}
\hline \hline Weight & Male & Female \\
\hline Light & $-60 \mathrm{~kg},-66 \mathrm{~kg}$ & $-48 \mathrm{~kg},-52 \mathrm{~kg}$ \\
\hline Middle & $-73 \mathrm{~kg},-81 \mathrm{~kg}$ & $-57 \mathrm{~kg},-63 \mathrm{~kg}$ \\
\hline Heavy & $-90 \mathrm{~kg}, \pm 100 \mathrm{~kg}$ & $-70 \mathrm{~kg}, \pm 78 \mathrm{~kg}$ \\
\hline \hline
\end{tabular}




\section{자료분석 방법}

본 연구에서 수집된 자료를 SPSS Statistics 20을 이 용하여 통계적 유의수준 0.05 에서 양측 검정하였다. 자 료의 일반적 특성 및 변수의 평균, 표준편차 등은 기술통 계(descriptive analysis)를 이용하였으며, 세계유도선 수들의 기술 유형에 따른 일반적 특성, 대회, 결과, 시간 에 대한 차이 분석은 카이스퀘어 검정 $\left(X^{2}\right.$-test $)$ 을 실시 하였다. 기술 시간에 대한 집단 간 차이를 알아보기 위하 여 일원분산분석 (One-way ANOVA)을 보수적 사후검정 법인 Scheffe 검정과 함께 사용하여 기술 시간과 일반적 특성, 대회, 결과, 기술 유형별 비교를 통해 얻은 결과를 도출하였다.

\section{연구결과}

\section{기술 유형에 따른 차이}

1. 성별, 체급 특성 차이

득점 기술 유형의 일반적 특성에 대한 비교 결과, 성별 $\left(X^{2}=723.104, \mathrm{p}=.000\right)$, 체급 $\left(X^{2}=354.940, \mathrm{p}=.000\right)$ 모두에서 통계적으로 유의한 차이가 있었다. 다음의
〈Table 4〉는 기술 유형에 따른 성별, 체급에 관한 빈도와 비율에 대해 알아보기 위한 빈도분석과 교차분석, 카이스 퀘어 $\left(X^{2}\right)$ 검증 결과를 정리한 것이다. 기술 유형은 발 기 술 $(9,235$ 회), 손 기술 $(7,045$ 회), 누르기 $(4,165$ 회), 모 로누우며메치기(2,938회), 허리 기술(2,450회), 바로누 우며메치기(1,884회), 꺾기(854회), 조르기(777회)순 이며, 남녀 모두 발 기술에 의한 기술 유형이 가장 많았 고, 손 기술(남자 $28 \%$, 여자 $18.4 \%$ )과 누르기(남자 $10.9 \%$, 여자 $18.8 \%$ )에서 큰 차이를 보였다. 체급에 따 른 기술 유형 비교 결과 체급이 높아질수록 손 기술의 비 율이 낮게 나타났으며, 누르기 비율은 높게 나타났다.

\section{2. 대회, 연도, 대륙별 특성 차이}

득점 기술 유형의 대회, 연도, 대륙에 대한 비교 결과, 대회 $\left(X^{2}=50.182, \mathrm{p}=.006\right), \quad$ 연도 $\left(X^{2}=362.075\right.$, $\mathrm{p}=.000)$, 대륙 $\left(X^{2}=249.521, \mathrm{p}=.000\right)$ 모두에서 통계 적으로 유의한 차이가 있었다. 다음의 〈Table 5〉는 기술 유형에 따른 대회, 연도, 대륙에 관한 빈도와 비율에 대해 알아보기 위한 빈도분석과 교차분석, 카이스퀘어 검증 결 과를 정리한 것이다. 5 개 대회별 분석 결과 올림픽경기에 서 꺾기 $(17.8 \%)$, 조르기 $(3.3 \%)$, 누르기 $(6.0 \%)$ 등 굳히 기 기술 비율이 다른 대회에 비해 높게 나타났다. 또한 연 도가 진행될수록 손 기술과 허리 기술의 비율이 높아졌

Table 4. Comparison of general characteristics of technical type

$\mathrm{n}(\%)$

\begin{tabular}{|c|c|c|c|c|c|c|c|c|c|c|}
\hline \multirow[b]{2}{*}{ Characteristics } & \multirow[b]{2}{*}{ Categories } & \multicolumn{8}{|c|}{ Technical type } & \multirow[b]{2}{*}{ Total } \\
\hline & & $\begin{array}{c}V_{1} \\
\mathrm{n}=7,045\end{array}$ & $\begin{array}{c}V_{2} \\
\mathrm{n}=2,450\end{array}$ & $\begin{array}{c}V_{3} \\
\mathrm{n}=9,235\end{array}$ & $\begin{array}{c}V_{4} \\
\mathrm{n}=2,938\end{array}$ & $\begin{array}{c}V_{5} \\
\mathrm{n}=1,884\end{array}$ & $\begin{array}{c}V_{6} \\
\mathrm{n}=4,165\end{array}$ & $\begin{array}{c}V_{7} \\
\mathrm{n}=777\end{array}$ & $\begin{array}{c}V_{8} \\
\mathrm{n}=854\end{array}$ & \\
\hline \multirow{3}{*}{ Gender } & Male & $\begin{array}{l}4,787 \\
(28.0)\end{array}$ & $\begin{array}{l}1,415 \\
(8.3)\end{array}$ & $\begin{array}{l}5,359 \\
(31.4)\end{array}$ & $\begin{array}{l}1,647 \\
(9.6)\end{array}$ & $\begin{array}{c}1,242 \\
(7.3)\end{array}$ & $\begin{array}{l}1,859 \\
(10.9)\end{array}$ & $\begin{array}{l}392 \\
(2.3)\end{array}$ & $\begin{array}{c}384 \\
(2.2)\end{array}$ & $\begin{array}{c}17,085 \\
(100)\end{array}$ \\
\hline & Female & $\begin{array}{l}2,258 \\
(18.4)\end{array}$ & $\begin{array}{l}1,035 \\
(8.4)\end{array}$ & $\begin{array}{l}3,876 \\
(31.6)\end{array}$ & $\begin{array}{l}1,291 \\
(10.5)\end{array}$ & $\begin{array}{l}642 \\
(5.2)\end{array}$ & $\begin{array}{l}2,306 \\
(18.8)\end{array}$ & $\begin{array}{l}385 \\
(3.1)\end{array}$ & $\begin{array}{l}470 \\
(3.8)\end{array}$ & $\begin{array}{c}12,263 \\
(100)\end{array}$ \\
\hline & & & & & & & & \multicolumn{3}{|c|}{$X^{2}=723.104 \mathrm{df}=7 \mathrm{p}<.001$} \\
\hline \multirow{3}{*}{ Weight } & Light & $\begin{array}{l}2,242 \\
(26.8) \\
2,323\end{array}$ & $\begin{array}{l}776 \\
(9.3) \\
724\end{array}$ & $\begin{array}{l}2,444 \\
(29.3) \\
3,050\end{array}$ & $\begin{array}{c}784 \\
(9.4) \\
771\end{array}$ & $\begin{array}{c}618 \\
(7.4) \\
638\end{array}$ & $\begin{array}{c}968 \\
(11.6) \\
1,247\end{array}$ & $\begin{array}{c}210 \\
(2.5) \\
297\end{array}$ & $\begin{array}{c}312 \\
(3.7) \\
279\end{array}$ & $\begin{array}{l}8,354 \\
(100) \\
9,329\end{array}$ \\
\hline & Heavy & $\begin{array}{l}(24.9) \\
2,480 \\
(21.3)\end{array}$ & $\begin{array}{c}(7.8) \\
950 \\
(8.1)\end{array}$ & $\begin{array}{l}(32.7) \\
3,741 \\
(32.1)\end{array}$ & $\begin{array}{l}(8.3) \\
1,383 \\
(11.9)\end{array}$ & $\begin{array}{c}(6.8) \\
628 \\
(5.4)\end{array}$ & $\begin{array}{l}(13.4) \\
1,950 \\
(16.7)\end{array}$ & $\begin{array}{c}(3.2) \\
270 \\
(2.3)\end{array}$ & $\begin{array}{c}(3.0) \\
263 \\
(2.3)\end{array}$ & $\begin{array}{c}(100) \\
11,665 \\
(100)\end{array}$ \\
\hline & & & & & & & & \multicolumn{3}{|c|}{$X^{2}=354.940 \mathrm{df}=14 \mathrm{p}<.001$} \\
\hline
\end{tabular}

$V_{1}$ : Te-waza, $V_{2}$ : Koshi-waza, $V_{3}$ : Ashi-waza, $V_{4}$ : Yoko-sutemi-waza, $V_{5}$ : Ma-sutemi-waza, $V_{6}:$ Osaekomi-waza, $V_{7}:$ Shime-waza, $V_{8}:$ Kansetsu-waza 
Table 5. Comparison of competition, year, continent characteristic of technical type

$\mathrm{n}(\%)$

\begin{tabular}{|c|c|c|c|c|c|c|c|c|c|c|}
\hline \multirow[b]{2}{*}{ Characteristics } & \multirow[b]{2}{*}{ Categories } & \multicolumn{8}{|c|}{ Technical type } & \multirow[b]{2}{*}{ Total } \\
\hline & & $\begin{array}{c}V_{1} \\
\mathrm{n}=7,045\end{array}$ & $\begin{array}{c}V_{2} \\
\mathrm{n}=2,450\end{array}$ & $\begin{array}{c}V_{3} \\
\mathrm{n}=9,235\end{array}$ & $\begin{array}{c}V_{4} \\
\mathrm{n}=2,938\end{array}$ & $\begin{array}{c}V_{5} \\
\mathrm{n}=1,884\end{array}$ & $\begin{array}{c}V_{6} \\
\mathrm{n}=4,165\end{array}$ & $\begin{array}{c}V_{7} \\
\mathrm{n}=777\end{array}$ & $\begin{array}{c}V_{8} \\
\mathrm{n}=854\end{array}$ & \\
\hline \multirow{5}{*}{ Competition } & GP & $\begin{array}{l}3,474 \\
(24.0)\end{array}$ & $\begin{array}{l}1,169 \\
(8.1)\end{array}$ & $\begin{array}{l}4,622 \\
(32.0)\end{array}$ & $\begin{array}{l}1,462 \\
(10.1)\end{array}$ & $\begin{array}{l}914 \\
(6.3)\end{array}$ & $\begin{array}{l}1,965 \\
(13.6)\end{array}$ & $\begin{array}{l}409 \\
(2.8)\end{array}$ & $\begin{array}{l}446 \\
(3.1)\end{array}$ & $\begin{array}{c}14,461 \\
(100)\end{array}$ \\
\hline & GS & $\begin{array}{l}2,282 \\
(24.0)\end{array}$ & $\begin{array}{c}833 \\
(8.8)\end{array}$ & $\begin{array}{l}2,959 \\
(31.1)\end{array}$ & $\begin{array}{c}949 \\
(10.0)\end{array}$ & $\begin{array}{l}590 \\
(6.2)\end{array}$ & $\begin{array}{l}1,409 \\
(14.8)\end{array}$ & $\begin{array}{l}236 \\
(2.5)\end{array}$ & $\begin{array}{l}256 \\
(2.7)\end{array}$ & $\begin{array}{l}9,514 \\
(100)\end{array}$ \\
\hline & WC & $\begin{array}{c}962 \\
(24.2)\end{array}$ & $\begin{array}{l}343 \\
(8.6)\end{array}$ & $\begin{array}{l}1,232 \\
(31.0)\end{array}$ & $\begin{array}{l}385 \\
(9.7)\end{array}$ & $\begin{array}{l}270 \\
(6.8)\end{array}$ & $\begin{array}{c}572 \\
(14.4)\end{array}$ & $\begin{array}{l}101 \\
(2.5)\end{array}$ & $\begin{array}{l}103 \\
(2.6)\end{array}$ & $\begin{array}{l}3,968 \\
(100)\end{array}$ \\
\hline & MT & $\begin{array}{c}257 \\
(24.0)\end{array}$ & $\begin{array}{c}83 \\
(7.7)\end{array}$ & $\begin{array}{c}336 \\
(31.3)\end{array}$ & $\begin{array}{l}105 \\
(9.8)\end{array}$ & $\begin{array}{c}83 \\
(7.7)\end{array}$ & $\begin{array}{c}160 \\
(14.9)\end{array}$ & $\begin{array}{c}20 \\
(1.9)\end{array}$ & $\begin{array}{c}29 \\
(2.7)\end{array}$ & $\begin{array}{l}1,073 \\
(100)\end{array}$ \\
\hline & OG & $\begin{array}{c}70 \\
(21.1)\end{array}$ & $\begin{array}{c}22 \\
(6.6)\end{array}$ & $\begin{array}{c}86 \\
(25.9)\end{array}$ & $\begin{array}{c}37 \\
(11.1)\end{array}$ & $\begin{array}{c}27 \\
(8.1)\end{array}$ & $\begin{array}{c}59 \\
(17.8)\end{array}$ & $\begin{array}{c}11 \\
(3.3)\end{array}$ & $\begin{array}{c}20 \\
(6.0)\end{array}$ & $\begin{array}{c}332 \\
(100)\end{array}$ \\
\hline \multicolumn{11}{|c|}{$X^{2}=50.182 \mathrm{df}=28 \mathrm{p}<.01$} \\
\hline \multirow{6}{*}{ Year } & 2016 & $\begin{array}{c}760 \\
(19.4)\end{array}$ & $\begin{array}{l}288 \\
(7.3)\end{array}$ & $\begin{array}{l}1,159 \\
(29.5)\end{array}$ & $\begin{array}{l}369 \\
(9.4)\end{array}$ & $\begin{array}{c}197 \\
(5.0)\end{array}$ & $\begin{array}{c}819 \\
(20.9)\end{array}$ & $\begin{array}{l}140 \\
(3.6)\end{array}$ & $\begin{array}{c}195 \\
(5.0)\end{array}$ & $\begin{array}{l}3,927 \\
(100)\end{array}$ \\
\hline & 2017 & $\begin{array}{l}1,503 \\
(23.4)\end{array}$ & $\begin{array}{l}532 \\
(8.3)\end{array}$ & $\begin{array}{l}1,995 \\
(31.1)\end{array}$ & $\begin{array}{c}674 \\
(10.5)\end{array}$ & $\begin{array}{l}386 \\
(6.0)\end{array}$ & $\begin{array}{c}980 \\
(15.3)\end{array}$ & $\begin{array}{l}163 \\
(2.5)\end{array}$ & $\begin{array}{l}182 \\
(2.8)\end{array}$ & $\begin{array}{l}6,415 \\
(100)\end{array}$ \\
\hline & 2018 & $\begin{array}{l}2,047 \\
(24.0)\end{array}$ & $\begin{array}{l}713 \\
(8.4)\end{array}$ & $\begin{array}{l}2,848 \\
(33.4)\end{array}$ & $\begin{array}{l}817 \\
(9.6)\end{array}$ & $\begin{array}{l}567 \\
(6.6)\end{array}$ & $\begin{array}{l}1,108 \\
(13.0)\end{array}$ & $\begin{array}{l}222 \\
(2.6)\end{array}$ & $\begin{array}{l}215 \\
(2.5)\end{array}$ & $\begin{array}{l}8,537 \\
(100)\end{array}$ \\
\hline & 2019 & $\begin{array}{l}2,325 \\
(26.2)\end{array}$ & $\begin{array}{c}765 \\
(8.6)\end{array}$ & $\begin{array}{l}2,739 \\
(30.9)\end{array}$ & $\begin{array}{c}910 \\
(10.3)\end{array}$ & $\begin{array}{c}626 \\
(7.1)\end{array}$ & $\begin{array}{l}1,074 \\
(12.1)\end{array}$ & $\begin{array}{l}210 \\
(2.4)\end{array}$ & $\begin{array}{l}217 \\
(2.4)\end{array}$ & $\begin{array}{l}8,866 \\
(100)\end{array}$ \\
\hline & 2020 & $\begin{array}{c}410 \\
(25.6)\end{array}$ & $\begin{array}{c}152 \\
(9.5) \\
\end{array}$ & $\begin{array}{c}494 \\
(30.8) \\
\end{array}$ & $\begin{array}{c}168 \\
(10.5) \\
\end{array}$ & $\begin{array}{c}108 \\
(6.7) \\
\end{array}$ & $\begin{array}{c}184 \\
(11.5) \\
\end{array}$ & $\begin{array}{c}42 \\
(2.6) \\
\end{array}$ & $\begin{array}{c}45 \\
(2.8) \\
\end{array}$ & $\begin{array}{l}1603 \\
(100)\end{array}$ \\
\hline & & & & & & & & $X^{2}$ & $2.075 \mathrm{~d}$ & $8 \mathrm{p}<.00$ \\
\hline \multirow{7}{*}{ Continent } & Independent & $\begin{array}{c}6 \\
(28.6)\end{array}$ & $\begin{array}{c}2 \\
(9.5)\end{array}$ & $\begin{array}{c}3 \\
(14.3)\end{array}$ & $\begin{array}{c}4 \\
(19.0)\end{array}$ & $\begin{array}{c}3 \\
(14.3)\end{array}$ & $\begin{array}{c}3 \\
(14.3)\end{array}$ & $\begin{array}{c}0 \\
(0.0)\end{array}$ & $\begin{array}{c}0 \\
(0.0)\end{array}$ & $\begin{array}{c}21 \\
(100)\end{array}$ \\
\hline & S-America & $\begin{array}{c}495 \\
(29.0)\end{array}$ & $\begin{array}{c}125 \\
(7.3)\end{array}$ & $\begin{array}{c}573 \\
(33.5)\end{array}$ & $\begin{array}{c}172 \\
(10.1)\end{array}$ & $\begin{array}{c}76 \\
(4.4)\end{array}$ & $\begin{array}{c}181 \\
(10.6)\end{array}$ & $\begin{array}{c}46 \\
(2.7)\end{array}$ & $\begin{array}{c}40 \\
(2.3)\end{array}$ & $\begin{array}{l}1,708 \\
(100)\end{array}$ \\
\hline & N-America & $\begin{array}{c}340 \\
(22.9)\end{array}$ & $\begin{array}{c}136 \\
(9.1)\end{array}$ & $\begin{array}{c}453 \\
(30.5)\end{array}$ & $\begin{array}{c}145 \\
(9.8)\end{array}$ & $\begin{array}{c}89 \\
(6.0)\end{array}$ & $\begin{array}{c}236 \\
(15.9)\end{array}$ & $\begin{array}{c}43 \\
(2.9)\end{array}$ & $\begin{array}{c}45 \\
(3.0)\end{array}$ & $\begin{array}{l}1,487 \\
(100)\end{array}$ \\
\hline & Asia & $\begin{array}{l}2,294 \\
(26.4)\end{array}$ & $\begin{array}{c}681 \\
(7.8)\end{array}$ & $\begin{array}{l}2,689 \\
(31.0)\end{array}$ & $\begin{array}{c}741 \\
(8.5)\end{array}$ & $\begin{array}{c}504 \\
(5.8)\end{array}$ & $\begin{array}{l}1,358 \\
(15.6)\end{array}$ & $\begin{array}{c}156 \\
(1.8)\end{array}$ & $\begin{array}{c}257 \\
(3.0)\end{array}$ & $\begin{array}{l}8,680 \\
(100)\end{array}$ \\
\hline & Africa & $\begin{array}{c}128 \\
(20.3)\end{array}$ & $\begin{array}{c}51 \\
(8.1)\end{array}$ & $\begin{array}{c}212 \\
(33.6)\end{array}$ & $\begin{array}{c}88 \\
(13.9)\end{array}$ & $\begin{array}{c}65 \\
(10.3)\end{array}$ & $\begin{array}{c}65 \\
(10.3)\end{array}$ & $\begin{array}{c}15 \\
(2.4)\end{array}$ & $\begin{array}{c}7 \\
(1.1)\end{array}$ & $\begin{array}{c}631 \\
(100)\end{array}$ \\
\hline & Oceania & $\begin{array}{c}28 \\
(24.6)\end{array}$ & $\begin{array}{c}12 \\
(10.5)\end{array}$ & $\begin{array}{c}32 \\
(28.1)\end{array}$ & $\begin{array}{c}19 \\
(16.7)\end{array}$ & $\begin{array}{c}2 \\
(1.8)\end{array}$ & $\begin{array}{c}12 \\
(10.5)\end{array}$ & $\begin{array}{c}7 \\
(6.1)\end{array}$ & $\begin{array}{c}2 \\
(1.8)\end{array}$ & $\begin{array}{c}114 \\
(100)\end{array}$ \\
\hline & Europe & $\begin{array}{l}3,754 \\
(22.5)\end{array}$ & $\begin{array}{c}1,443 \\
(8.6)\end{array}$ & $\begin{array}{l}5,273 \\
(31.6)\end{array}$ & $\begin{array}{l}1,769 \\
(10.6)\end{array}$ & $\begin{array}{c}1,145 \\
(6.9)\end{array}$ & $\begin{array}{l}2,310 \\
(13.8)\end{array}$ & $\begin{array}{c}510 \\
(3.1)\end{array}$ & $\begin{array}{c}503 \\
(3.0)\end{array}$ & $\begin{array}{c}16,707 \\
(100)\end{array}$ \\
\hline
\end{tabular}

$V_{1}$ : Te-waza, $V_{2}$ : Koshi-waza, $V_{3}$ : Ashi-waza, $V_{4}$ : Yoko-sutemi-waza, $V_{5}$ : Ma-sutemi-waza, $V_{6}$ : Osaekomi-waza, $V_{7}:$ Shime-waza, $V_{8}:$ Kansetsu-waza GP : Grand Prix, GS: Grand Slam WC: World Championships MT: Masters OG: Olympic Games 
Table 6. Comparison of time interval, result, tournament characteristic of technical type

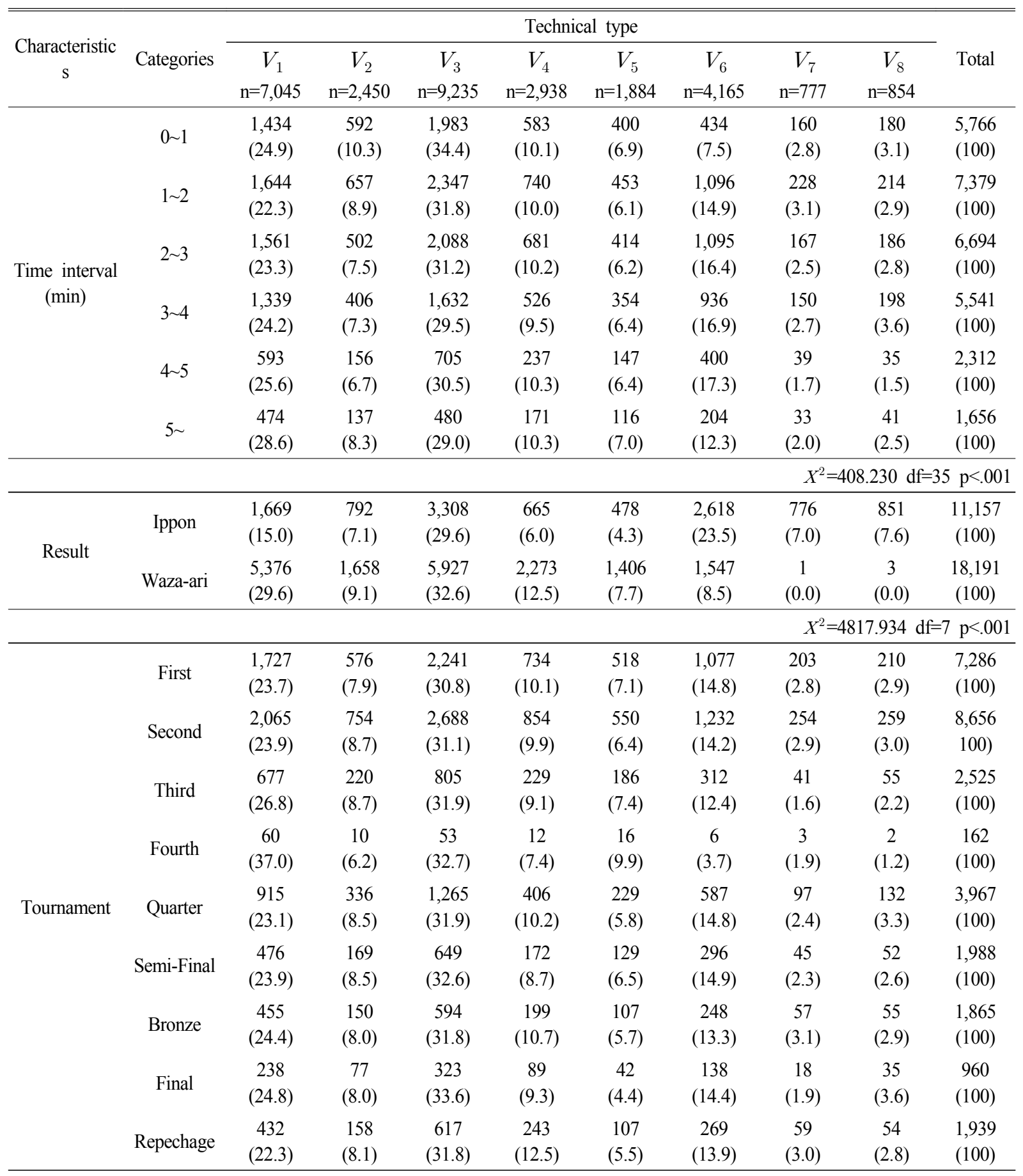

$X^{2}=133.938 \quad \mathrm{df}=56 \mathrm{p}<.001$

$V_{1}$ : Te-waza, $V_{2}$ : Koshi-waza, $V_{3}$ : Ashi-waza, $V_{4}$ : Yoko-sutemi-waza, $V_{5}$ : Ma-sutemi-waza, $V_{6}$ : Osaekomi-waza, $V_{7}$ :

Shime-waza, $V_{8}$ : Kansetsu-waza 
고, 누르기는 줄어드는 양상을 보였다. 대륙별 기술 유형 을 살펴보면 남아메리카는 손 기술과 발 기술, 북아메리 카는 누르기 기술, 아시아는 누르기와 꺾기 기술, 아프리 카는 바로누우며메치기와 발 기술, 오세아니아는 모로누 우며메치기와 허리 기술, 유럽은 조르기와 꺾기 기술이 상대적으로 높은 비율을 나타냈다.

\section{3. 시간, 결과, 토너먼트 특성 차이}

득점 기술 유형에 따른 기술 시간, 기술 결과, 토너먼 트에 대한 비교 결과, 기술 시간 $\left(X^{2}=408.230\right.$, $\mathrm{p}=.000)$, 기술 결과 $\left(X^{2}=4817.934, \mathrm{p}=.000\right)$, 토너먼 트 $\left(X^{2}=133.938, \mathrm{p}=.000\right)$ 모두에서 통계적으로 유의 한 차이가 있었다. 다음의 〈Table 6>은 기술 유형에 따른 기술 시간, 기술 결과 토너먼트에 관한 빈도와 비율에 대 해 알아보기 위한 빈도분석과 교차분석, 카이스퀘어 검증 결과를 정리한 것이다. 6 가지 시간 분류에 대한 분석 결 과 $1 \sim 2$ 분 사이에서 가장 많은 7,379 회의 기술이 득점으 로 연결되었으며, 2 3분 사이에서 6,694회로 두 번째로 높게 나타났다. 0 1분 사이인 극초반을 제외하고 시간 이 흐름에 따라 손 기술의 빈도가 늘어났으며, 허리 기술 사용 빈도는 줄어드는 양상을 보였다. 한판과 절반으로 구분된 기술 결과에 대한 분석 결과 메치기 기술(손 기술, 허리 기술, 발 기술, 모로누우며메치기, 바로누우며메치 기 기술은 절반이 상대적으로 높게 나타났고, 굳히기 기 술(누르기, 조르기, ㄲㄲㄲㄱㅣ)은 한판이 상대적으로 높은 비 율로 나타났다. 예선과 8강, 준결승, 결승, 동메달결정 전, 패자부활전에 대한 분석 결과 준결승과 결승으로 갈 수록 손 기술과 발 기술의 비율이 상대적으로 높게 나타 나는 양상을 보였다. Fig 1.은 각 독립변수별로 구분된 집단 간의 득점 기술 유형에 대한 그래프이다.

\section{기술 시간에 따른 차이}

\section{1. 성별, 체급 특성 차이}

자료수집 대상의 일반적 특성(성별, 체급)에 따른 기 술 시간의 차이를 알아보기 위하여 총 50,828 득점 기술 을 바탕으로 일원변량분석을 실시하였다. 분석 결과 모든 부분에서 통계적으로 유의한 차이를 나타냈다( $\mathrm{p}<.05)$. 〈Table 7〉은 성별, 체급으로 구분된 집단 간의 득점 기술

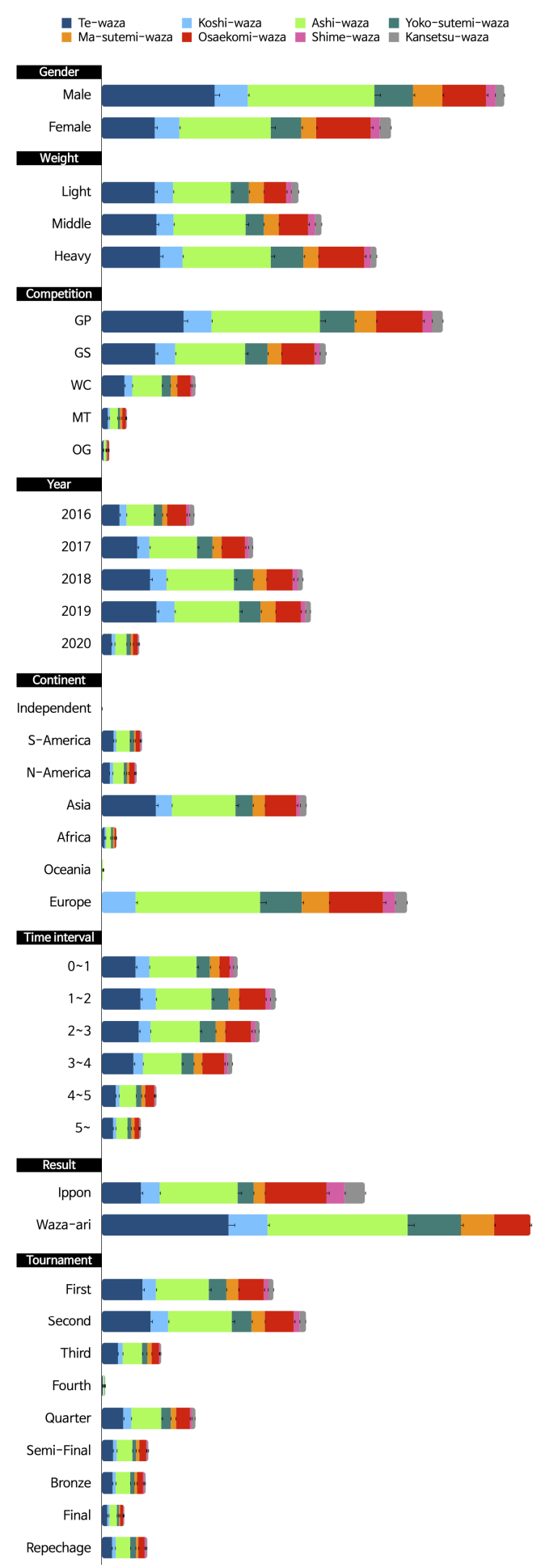

Fig. 1. Diagram showing characteristic of technical type 
Table 7. Comparison of general characteristics of technical time

(Unit: seconds)

\begin{tabular}{cccccc}
\hline \hline Characteristics & Categories & $\mathrm{M} \pm \mathrm{SD}$ & $F$-value & $p$-value & $\begin{array}{c}\text { post-hoc } \\
\text { (Scheffe) }\end{array}$ \\
\hline \multirow{2}{*}{ Gender } & (1) Male & $148.75 \pm 92.5$ & \multirow{2}{*}{131.011} & .001 & $\mathrm{~N} / \mathrm{A}$ \\
& (2) Female & $136.60 \pm 93.8$ & & & \\
\multirow{3}{*}{ Weight } & (1) Light & $147.97 \pm 98.33$ & & \\
& (2) Middle & $148.31 \pm 95.35$ & 58.463 & .001 & (2) (1) $>$ (3) \\
& (3) Heavy & $136.53 \pm 86.98$ & & & \\
\hline \hline
\end{tabular}

시간에 대한 평균과 표준편차, 일원분산분석 검정 결과를 함께 제시한 것이다. 성별의 경우 남자(148.75초) 보다 여자(136.60초) 선수의 득점으로 이어지는 기술 시간이 평균 12 초가량 더 짧게 나타났다. 체급별 차이를 살펴보 면 헤비급(136.53초)이 가장 낮게 나타났고, 경량급 (147.97초)과 중량급(148.31초)은 통계적으로 차이가 나타나지 않았다(p>.05).
2. 대회, 연도, 대륙별 특성 차이

대회, 연도, 대륙에 따른 기술 시간의 차이를 알아보기 위하여 총 50,828 득점 기술을 바탕으로 일원변량분석을 실시하였다. 분석 결과 모든 부분에서 통계적으로 유의한 차이를 나타냈다 $(\mathrm{p}<.05)$. 〈Table 8>은 대회, 연도, 대륙 으로 구분된 집단 간의 득점 기술 시간에 대한 평균과 표 준편차, 일원분산분석 검정 결과를 함께 제시한 것이다. 대회별 득점 기술 시간을 살펴보면 마스터즈 대회

Table 8. Comparison of competition, year, continent characteristic of technical time

(Unit: seconds)

\begin{tabular}{|c|c|c|c|c|c|}
\hline Characteristics & Categories & $\mathrm{M} \pm \mathrm{SD}$ & $F$-value & $p$-value & $\begin{array}{l}\text { post-hoc } \\
\text { (Scheffe) }\end{array}$ \\
\hline \multirow{5}{*}{ Competition } & (1) GP & $141.51 \pm 91.75$ & \multirow{5}{*}{14.665} & \multirow{5}{*}{.001} & \multirow{5}{*}{ (4) $>$ (5)(2)(3) (1) } \\
\hline & (2) GS & $144.88 \pm 92.52$ & & & \\
\hline & (3) $\mathrm{WC}$ & $142.06 \pm 95.69$ & & & \\
\hline & (4) MT & $161.51 \pm 105.98$ & & & \\
\hline & (5) $\mathrm{OG}$ & $149.22 \pm 93.28$ & & & \\
\hline \multirow{5}{*}{ Year } & (1) 2016 & $144.62 \pm 84.15$ & \multirow{5}{*}{2.688} & \multirow{5}{*}{.030} & \multirow{5}{*}{ N/A } \\
\hline & (2) 2017 & $146.55 \pm 90.73$ & & & \\
\hline & (3) 2018 & $142.60 \pm 95.76$ & & & \\
\hline & (4) 2019 & $142.82 \pm 95.83$ & & & \\
\hline & (5) 2020 & $140.82 \pm 94.34$ & & & \\
\hline \multirow{7}{*}{ Continent } & (1) Independent & $133.82 \pm 77.07$ & \multirow{7}{*}{7.169} & \multirow{7}{*}{.001} & \multirow{7}{*}{$\begin{array}{l}\text { (4) } 6 \text { ) }>\text { (7)(2) }> \\
\text { (3) }>\text { (1) }>\text { (5) }\end{array}$} \\
\hline & (2) S-America & $142.01 \pm 92.98$ & & & \\
\hline & (3) N-America & $138.68 \pm 92.29$ & & & \\
\hline & (4) Asia & $147.63 \pm 95.80$ & & & \\
\hline & (5) Africa & $128.24 \pm 84.41$ & & & \\
\hline & (6) Oceania & $146.48 \pm 85.49$ & & & \\
\hline & (7) Europe & $142.71 \pm 92.27$ & & & \\
\hline
\end{tabular}

GP : Grand Prix, GS: Grand Slam WC: World Championships MT: Masters OG: Olympic Games 
(161.51초)에서 득점으로 이어지는 기술 시간이 가장 길 게 나타나며 다른 대회와 통계적으로 유의한 차이를 나타 냈다( $\mathrm{p}<.05)$. 연도별 득점 기술 시간에서는 일원분산분 석에서만 통계적으로 유의한 차이 $(\mathrm{p}<.05)$ 를 나타냈을 뿐, 사후검증결과에서는 유의한 차이를 보이지 않았다. 선수의 소속 대륙별 득점 기술 시간을 살펴보면 아프리카 대륙 선수들의 기술시간이 가장 짧게, 아시아대륙 선수들 의 기술 시간이 가장 길게 나타났으며, 대륙별 사후분석 결과 아프리카(128.24초), 유럽(142.71초), 아시아 (147.63초), 북아메리카(138.68초)에서 통계적으로 유 의한 차이를 나타냈다.

3. 득점 기술, 결과, 토너먼트 특성 차이

득점 기술, 기술 결과, 토너먼트에 따른 기술 시간의 차이를 알아보기 위하여 총 50,828 득점 기술을 바탕으로
일원변량분석을 실시하였다. 분석 결과 모든 부분에서 통 계적으로 유의한 차이를 나타냈다(p<.05). 〈Table 9>은 득점 기술, 기술 결과, 토너먼트로 구분된 집단 간의 득점 기술 시간에 대한 평균과 표준편차, 일원분산분석 검정 결과를 함께 제시한 표이다. 득점 기술별 시간을 살펴보 면 누르기(157.01초), 손 기술(147.66초)에 의해 득점 으로 이어지는 기술 시간이 허리(134.28초), 조르기 (136.42초), 꺾기(139.80초), 발(139.82초), 바로누우 며메치기(143.42초), 모로누우며메치기(144.49초)에 비해 득점으로 이어지는 기술 시간이 상대적으로 길게 나 타났으며 통계적으로 유의한 차이를 나타냈다( $\mathrm{p}<.05)$. 결과별 기술 시간의 차이를 살펴보면 절반(141.63초)이 한판(146.80)에 비해 평균 5초 정도 더 짧게 나타나며 통계적으로 유의한 차이를 나타냈다(p<.05). 토너먼트별 기술 시간의 차이는 예선 4차전(168.06초)과 준결승

Table 9. Comparison of technic, result, tournament characteristic of technical time

(Unit: seconds)

\begin{tabular}{|c|c|c|c|c|c|}
\hline Characteristics & Categories & $\mathrm{M} \pm \mathrm{SD}$ & $F$-value & $p$-value & $\begin{array}{l}\text { post-hoc } \\
\text { (Scheffe) }\end{array}$ \\
\hline \multirow{8}{*}{ Technical type } & (1) $V_{1}$ & $147.66 \pm 97.06$ & \multirow{8}{*}{21.047} & \multirow{8}{*}{.001} & \multirow{8}{*}{$\begin{array}{c}\text { (6)(1) }> \\
\text { (4)(3)(8)(7) }\end{array}$} \\
\hline & (2) $V_{2}$ & $134.28 \pm 95.54$ & & & \\
\hline & (3) $V_{3}$ & $139.82 \pm 91.89$ & & & \\
\hline & (4) $V_{4}$ & $144.49 \pm 93.52$ & & & \\
\hline & (5) $V_{5}$ & $143.42 \pm 92.89$ & & & \\
\hline & (6) $V_{6}$ & $157.01 \pm 82.04$ & & & \\
\hline & (7) $V_{7}$ & $136.42 \pm 86.74$ & & & \\
\hline & (8) $V_{8}$ & $139.80 \pm 87.41$ & & & \\
\hline \multirow{2}{*}{ Result } & (1) Ippon & $146.80 \pm 93.96$ & \multirow{2}{*}{23.007} & \multirow{2}{*}{.001} & \multirow{2}{*}{ N/A } \\
\hline & (2) Waza-ari & $141.63 \pm 92.73$ & & & \\
\hline \multirow{9}{*}{ Tournament } & (1) First & $135.09 \pm 87.29$ & \multirow{9}{*}{23.499} & \multirow{9}{*}{.001} & \multirow{9}{*}{$\begin{array}{c}\text { (4) } 8(6)> \\
(7)>\text { (5)(3)(2)(1) }\end{array}$} \\
\hline & (2) Second & $141.13 \pm 89.66$ & & & \\
\hline & (3) Third & $148.89 \pm 93.62$ & & & \\
\hline & (4) Fourth & $168.06 \pm 102.85$ & & & \\
\hline & (5) Quarter & $148.60 \pm 94.86$ & & & \\
\hline & (6) Semi-Final & $154.62 \pm 102.63$ & & & \\
\hline & (7) Bronze & $151.93 \pm 102.37$ & & & \\
\hline & (8) Final & $160.15 \pm 106.84$ & & & \\
\hline & (9) Repechage & $139.82 \pm 94.94$ & & & \\
\hline
\end{tabular}

$V_{1}$ : Te-waza, $V_{2}$ : Koshi-waza, $V_{3}$ : Ashi-waza, $V_{4}$ : Yoko-sutemi-waza, $V_{5}:$ Ma-sutemi-waza, $V_{6}$ : Osaekomi-waza, $V_{7}:$ Shime-waza, $V_{8}:$ Kansetsu-waza 
(154.62초), 결승(160.15초) 집단에서 기술 시간이 가 장 길게 나타나며 다른 집단에 비해 통계적으로 유의한 차이를 나타냈다(p<.05). Fig 2는 각 독립변수별로 구분 된 집단 간의 득점 기술 시간에 대한 그래프이다.

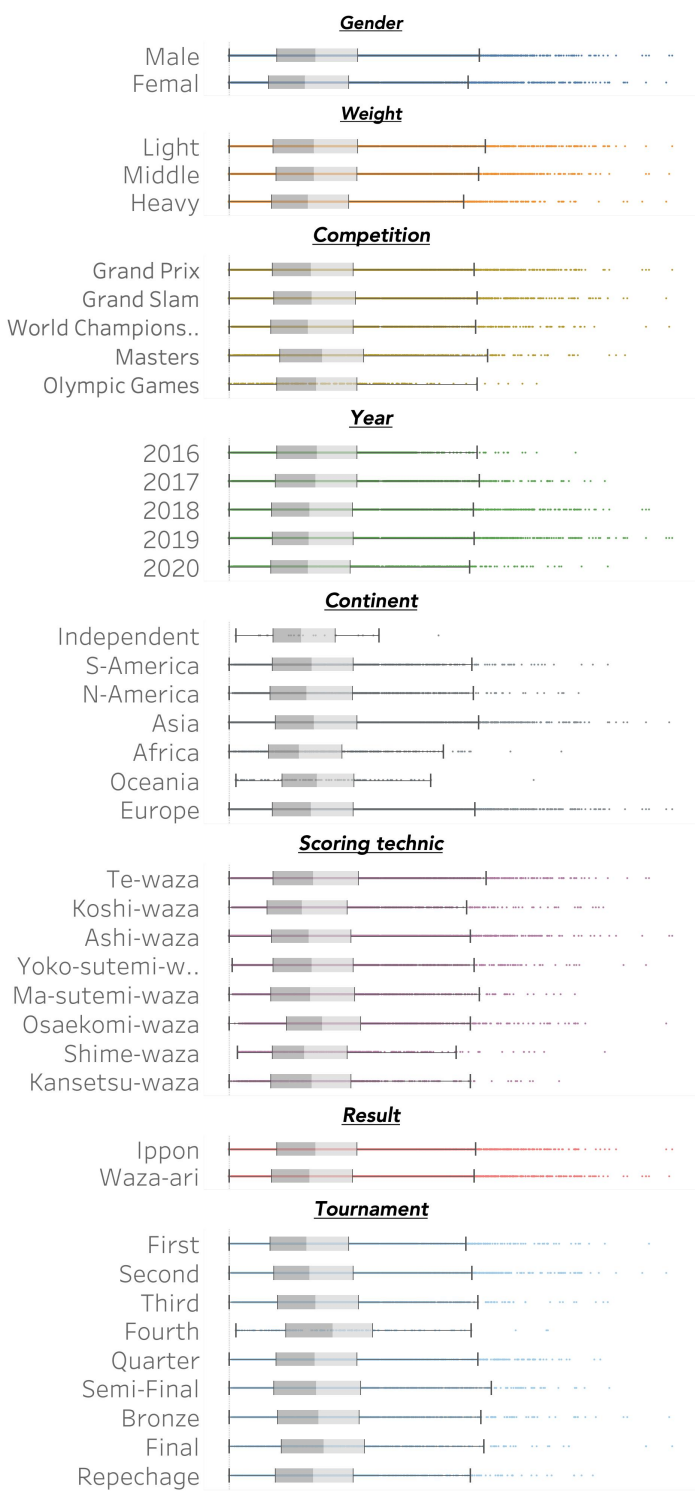

Fig. 2. Diagram showing characteristic of technical time

\section{논의}

본 연구는 2016년부터 2020년까지 국제유도연맹에서 제공하는 득점 기술 유형 및 시간 기록을 바탕으로 관련 요인별 차이를 알아보기 위하여 총 50,828 개의 득점 기 술을 분석해 집단 간의 차이를 검증하였다. 이 연구에서 도출한 결과에 대한 논의는 다음과 같다.

\section{기술 유형에 따른 차이}

유도 세계대회 출전 선수를 대상으로 득점 기술 유형 에 따른 차이를 분석한 결과 성별, 체급, 대회, 연도, 대 륙, 득점 시간, 기술 결과, 토너먼트의 모든 부분에서 통 계적으로 유의한 차이가 나타났다. Franchini et al.(2013)은 앞선 연구에서 스탠딩 자세에서의 메치기 기술이 그라운드에서의 굳히기 기술에 비해 더 많이 사용 된다고 보고했는데, 본 연구에서 기술 유형의 빈도분석 결과 발 기술, 손 기술, 누르기, 모로누우며메치기, 허리 기술, 바로누우며메치기, ㄲㄲㄲㄱㅣ, 조르기 순이며, 남녀 모 두 발 기술에 의한 기술 유형이 가장 많았다. 남자 선수는 손 기술이 여자 선수는 누르기와 발 기술의 비율이 상대 적으로 높게 나타났다. Yoon \& Lee(2004)는 한국 대학 유도연맹전의 사용 기술을 분석한 연구에서 남자 선수는 손 기술, 여자는 발 기술이 높게 사용되고 있다고 보고했 다. $\operatorname{Kim}(2013)$ 은 국가대표 선수들의 기술 유형을 분석 한 결과 발 기술의 득점이 높게 나타났다고 하였고, $\operatorname{Kim}(2005)$ 은 국내 남, 여 선수 모두 발 기술을 가장 많 이 사용하고 있다고 하여 본 연구의 결과와 맥락을 같이 한다. 체급에 따른 선행연구를 살펴보면 Kang(2014)은 런던올림픽에 출전한 국내 선수들의 기술 유형을 분석한 연구에서 중량급 선수들이 밭다리 걸기 기술의 빈도가 가 장 많다고 보고하였다. Lee \& Cho(2018)는 2015년 세 계선수권대회에 출전한 우수 여자 선수들을 분석한 결과 체급이 증가할수록 득점 기술의 빈도가 증가한다고 보고 했는데, 이러한 결과를 근력과 연관이 있다고 제언했다. 이에 더해 Lee \& Son(2020)은 국내 대학 엘리트 남자 유도 선수들의 체급별 운동능력을 비교한 연구에서 슬 관 절, 좌·우 굴근, 좌·우 신근에서 헤비급 집단이 경량급, 중 량급 집단에 비하여 유의하게 높다고 보고해 체급과 근력 
의 관계를 규명했다. 이 연구에서도 득점 기술 유형 비교 결과 체급이 높아질수록 손 기술의 비율이 낮게 나타났으 며, 누르기 비율은 높게 나타났다. 또한 체급이 증가함에 따라 기술 유형의 빈도 또한 증가하는 양상(경량급: 8,354회, 중량급: 9,329회, 헤비급: 11,665 회)을 보이 며 앞선 주장을 뒷받침한다. 5 개 대회별 분석 결과 올림 픽 경기에서 굳히기 기술 비율이 다른 대회에 비해 높게 나타났으며 연도가 진행될수록 손 기술과 허리 기술의 비 율이 높아졌고, 누르기는 줄어드는 양상을 보였다.

대륙별 기술 유형을 살펴보면 남아메리카는 손 기술과 발 기술, 북아메리카는 누르기 기술, 아시아는 누르기와 꺾기 기술, 아프리카는 바로누우며메치기와 발 기술, 오 세아니아는 모로누우며메치기와 허리 기술, 유럽은 조르 기와 꺾기 기술이 상대적으로 높은 비율을 나타냈다. Lee \& Cho(2018)는 2015년 세계선수권대회에 출전한 우수 여자 선수들을 분석한 결과 아시아 대륙의 선수들은 누르 기를 가장 많이 사용했다고 보고했는데, 아시아 대륙에서 누르기 기술의 비율이 높은 것은 힘이 좋은 유럽선수를 상대하는 데 있어 다리 기술이나 손 기술을 효과적으로 성공시키는데 어려워 이를 극복하기 위해 굳히기 기술의 일종인 누르기 기술을 효과적으로 구사하고 있는 것이라 제언했다. 또한 유럽 대륙의 선수들이 힘과 기술을 바탕 으로 기술을 효과적으로 구사해 기술을 성 공하여 득점하 는 비율이 가장 높다고 분석했는데, 이 연구에서도 유럽 의 득점 기술 빈도수가 가장 높게 나타났다(유럽: 16,707, 아시아: 8,680).

시간 분류에 대한 분석 결과 $1 \sim 3$ 분 사이에서 많은 득 점 (48\%)이 이루어졌으며, 극 초반을 제외하고 시간이 흐 름에 따라 손 기술의 빈도는 늘고, 허리 기술 사용 빈도는 줄어드는 양상을 보였다. 한판과 절반으로 구분된 기술 결과에 대한 분석 결과 메치기 기술은 절반으로, 굳히기 기술은 한판으로 연결되는 비율이 상대적으로 높았다. 또 한, 준결승과 결승으로 갈수록 손 기술과 발 기술의 비율 이 상대적으로 높게 나타나는 양상을 보였다.

\section{기술 시간에 따른 차이}

Marcon et al. (2010)은 최근까지 유도 경기에서 이루 어지는 기술 유형과 시간 유형을 분석한 연구는 없다고
지적하며 유도 경기에서 기술 시간을 평가하는 방법으로 경기 중에 일어나는 행동을 더 잘 이해할 수 있게 해줄 것 이라고 제언했고, Miarka et al.(2012)과 Del Vecchio et al.(2011)은 격투 스포츠에서의 시간 분석과 움직임 의 중요한 요소를 결합한 연구는 지금까지 거의 없다고 문제를 제기했다. Kim et al. (2000)는 유도경기 중 시간 의 흐름에 따라 경기 양상이나 득점 기술의 변화에 대한 연구의 필요성을 강조하며 유효 기술의 승부점인 시간 변 인을 고려한 기술 분석 연구가 수행돼야 할 필요성을 제 기했다. 이와 같이 대부분의 유도종목의 연구는 선수의 기술 유형과 득점 기술에 치우쳐져 있었고, 득점 또는 기 술이 발생한 시간에 대한 연구는 미비했다.

이에 본 연구에서는 기술 시간에 따른 독립변수들 간 차이를 비교하여 분석한 결과 성별, 체급, 대회, 연도, 대 륙, 득점 기술, 기술 결과, 토너먼트의 모든 부분에서 통 계적으로 유의한 차이를 나타냈다. 성별의 경우 남자 선 수의 기술 시간이 평균 12 초가량 더 길게 나타났으며, 체 급별 차이를 살펴보면 헤비급이 가장 낮았고, 중량급이 가장 길게 나타났다. 대회별 득점 시간을 살펴보면 마스 터즈 대회에서 득점으로 이어지는 기술 시간이 가장 길게 나타났으며, 연도별 득점 기술 시간 차이를 알아보기 위 한 사후검증 결과에서 유의한 차이가 나타나지 않았다. 대륙별 기술 시간은 아시아 대륙의 선수들이 가장 길게 나타났는데 이는 체력이 우수하고 지구력이 좋으며 굳히 기 기술이 강한 특성에서 비롯되었다고 판단된다. 득점 기술별 시간을 살펴보면 누르기와 손 기술에 의해 득점으 로 이어지는 기술 시간이 가장 길게 나왔으며, 허리 기술 과, 조르기 기술 시간이 상대적으로 짧게 나타났다. 결과 별 기술 시간의 차이를 살펴보면 절반이 한판에 비해 평 균 5 초 정도 더 짧게 나타났으며, 토너먼트별 기술 시간 의 차이는 중요한 경기일수록(예선4차전, 준결승, 결승) 기술 시간이 길어지는 양상을 보였다.

Segedi et al. (2014)은 일찍이 유도 종목에서 남녀 및 체급에 따라 기술의 유형과 구조적 특징이 다르기 때문에 훈련 시 개별적인 접근이 필요하며 이러한 훈련이 성공적 으로 적용되기 위해서 현재의 기술 유형과 스타일에 맞 춰 유도 경기를 분석할 필요가 있다고 제언했는데, 본 연 구의 기초 기록 자료를 바탕으로 다양한 분석 기법을 적 용할 필요가 있다고 판단된다. 최근 대한민국 대표팀의 
경기력은 과거에 비해 주춤하는 모습을 보이고 있다. 2016 리우데자네이루 올림픽에서는 2000년 시드니 올 림픽 이후 16 년 만에 금메달을 획득하지 못하고 대회를 마감했는데, 이는 1976년 몬트리올 올림픽 이후 최악의 성적으로 기록되었다. 이는 과거와 달리 최근 세계대회에 출전하는 선수들의 경기력과 기술 수준이 높아졌고, 절대 강자도, 절대 약자도 없이 평준화되고 있는 추세이다. 유 도는 주어진 시간 내 상대와 단판 승부를 펼치는데, 대부 분 한 번 또는 두 번의 공격으로 끝나는 경우가 많아 상대 에 대한 특성 파악과 기술 유형 분석이 중요하다. 세계 우 수 선수들의 기술 유형에 대한 철저한 분석과 연구를 통 해 자국 대표선수들이 올림픽을 포함한 국제 대회에서 높 은 경기력을 유지 하는데 도움을 줄 수 있을 것으로 사료 된다.

\section{결론 및 제언}

본 연구는 2016년부터 2020년까지 국제유도연맹에서 제공하는 공식 경기 기록을 바탕으로 득점 기술 유형 및 시간 기록을 바탕으로 관련 요인별 관계를 규명해 유도 기술의 특성을 분석하는데 목적이 있었다. 본 연구의 결 과를 토대로 내린 결론은 다음과 같다.

첫째, 득점 기술 유형에 따른 성별, 체급, 대회, 연도, 대륙, 득점 시간, 기술 시간, 토너먼트의 모든 부분에서 통계적으로 유의한 차이가 나타났으며, 메치기 기술에서 는 발 기술이 굳히기 기술에서는 누르기 기술의 득점 비 율이 가장 높았다.

둘째, 득점 기술 시간에 따른 성별, 체급, 대회, 연도, 대륙, 득점 기술, 기술 결과, 토너먼트의 모든 부분에서 통계적으로 유의한 차이가 나타났다. 특히 남자 선수의 기술 시간이 여자 선수에 비해 평균 12 초가량 더 길게 나 타났으며, 아시아 대륙의 선수들의 기술 시간이 가장 길 게 나타났다. 또한, 절반이 한판에 비해 평균 5 초 정도 더 짧게 나타났으며, 준결승과 결승 등 중요한 경기일수록 기술 시간이 길어지는 양상을 보였다.

결론적으로 이 연구를 통해 세계유도선수들의 기술 유 형과 시간에 대한 특성을 확인하였는데, 다양한 원인들에 의해 기술 유형과 시간에 영향을 미치고 있음을 알 수 있
었다. 특히 특정한 연도와 국가에 대한 자료가 아닌 수년 간에 걸친 기초자료와 연구 결과라는 점에서 괄목할 만한 점이다. 이를 바탕으로 유도 경기력 향상을 위해 우리나 라 선수들을 포함한 세계 우수 선수들의 기술 유형을 심 층적으로 분석하고 체계화하는 것이 필요하며, 국내선수 들과 세계 정상급 선수의 경기력 변인의 특성 차이에 대 한 분석이 이루어져 다가올 올림픽 현장에서의 빠르고 유 연한 대응이 가능한 시스템 구축에 대한 후속 연구가 필 요하다고 사료된다.

\section{참고문헌}

An. C. S. (2009). A demand volume of body composition and anaerobic capacity in high school judoists. Korean Alliance of Martial Arts, 11(1), 188-197.

Brousse, M., \& Matsumoto, D. R. (1999). Judo: a sport and a way of life. International judo federation.

Calmet, M., Miarka, B., \& Franchini, E. (2010). Modeling of grasps in judo contests. International Journal of Performance Analysis in Sport, 10, 229 - 240.

Del Vecchio, F.B., Hirata S.M., \& Franchini, E. (2011). Areview of time-motionanalysis and combat development in mixed martial arts matches at regional level tournaments. Perceptual and Motor technique, 112, 639 - 648.

Drid, P., Trivić, T., Obadov, S., \& Vujkov, S. (2013). Analysis of the judo olympic tournament for men, london 2012 retrospective. 1. Specific Rhytmic Gymnastics technique Acquisition Conditionallity in Preschool, 193.

Franchini E., Artioli G.G., \& Brito C.J. (2013), Judo com-bat: time-motion analysis and physiology. International Journal of Performance Analysis in Sport, 13(3), 624-641.

Hughes, M., \& Franks, I. M. (2004). Notational analysis of sport: Systems for better coaching and performance in sport. 2nd ed. London: Routlege.

Kang, S. K. (2014). Analysis of Judoist, Game Technic Contents Analysis in Korea National Judo Team (2012, London Olympic). Korea Journal of Physical Evaluation, 16(1), 121-130.

Kim, J. H., \& Choi, H. J. (2008). Reinterpretation of Winning and Losing Performances based on Different Data Ranges. Korean 
Journal of Measurement and Evaluation in Physical Education and Sport Science. 2015, 17(1), 1-12

Kim. B. G., \& Ha. C. S. (2010). The Effect of Training the Flow on Play Performance in Judo Athlete. Korean Society of Sport and Leissure Studies, 39(2), 765-774.

Kim. J. G. (2005). study on continental different of Judo competition techniques. Unpublished master's thesis, Yongin University, Yongin.

Kim. J. Y. (2013). An Analysis of Judo Match Scoring Patterns for National Judo Players. Unpublished master's thesis, Kyungnam University, Changwon.

Kim. K. H., Park. J. S., Kim. J. Y., \& Jang. S. H. (2010). The development and effect analysis of psychological skill training program for performance improvement of national judo player. The Journal of Korean Aliance of Martial Arts, 12(3), 185-203.

Kim. K. H., Yoon. J. D., \& An. C. S. (2000). A Study on the technique used in national and international Judo Competition. Korean Society Of Leisure Sport, 4(0), 19-33.

Kwon. M. S., Kim. E. H., \& Cho. D. H. (2002). A kinematics analysis of uchi-mata(inner thigh reaping throw) by kumi-kata types and Two different opponent's height in judo [2]. Korean Society of Sport Biomechnics, 12(2), 143-157.

Lee. D. I. (2010). ALiterture Reserch of the modern judo origin and korea judo develoment process. Unpublished master's thesis, Chonbuk University, Chonbuk .
Lee. H. C., \& Son. H. J. (2020). Comparison on iso kinetic muscular strength of knee joint and anaerobic exercise ability per weight in university elite male judo athletes. Journal of coaching development, 22(1), 110-116.

Lee. Y. K., \& Cho. M. S. (2018). An Analysis of excellent Women player's technical type contents in 2015 Judo World Championships. Sports Science, 35(2), 117-126.

Marcon, G., Franchini, E., Jardim, J. R., \& Neto, T. L. B. (2010). Structural analysis of action and time in sports: judo. Journal of quantitative analysis in sports, 6(4), 1-10.

Miarka, B., Panissa, V. L. G., Julio, U. F., Del Vecchio, F. B., Calmet, M., \& Franchini, E. (2012). A comparison of time-motion performance between age groups in judo matches. Journal of sports sciences, 30(9), 899-905.

Pereira Martins, F., de Souza, D. P., Scarano, L., Pinheiro de Campos, R., Bromley, S. J., Yuri Takito, M., \& Franchini, E. (2019). Techniques utilised at 2017 judo world championship and their classification: comparisons between sexes, weight categories, winners and non-winners. Ido Movement for Culture. Journal of Martial Arts Anthropology, 19(1), 58-65.

Segedi, I., Sertic, H., Franjic, D., Kustro, N., \& Rozac, D. (2014). Analysis of judo match for seniors. Journal of Combat Sports and Martial Arts, 2(5), 57-61.

Yoon. I. S., \& Lee. H. S. (2004). An Analysis for Scoring technique Per Weight of University Judo. The Yongln Unlverslty Journal of Martlal Arts Instltute, 15(1), 369-398. 


\title{
세계 유도 선수의 득점 기술 유형 및 시간 분석
}

\author{
김태완 ${ }^{1}$, 이승훈 ${ }^{2}$ \\ 1한국스포츠정책과학원 책임연구위원 \\ 2한국스포츠정책과학원 분석연구원
}

〔목적〕 본 연구는 최근 5년간의 주요 유도 세계대회 기록을 바탕으로 득점 기술과 득점 시간에 따른 일반적 특성 및 환경적 요소에 대한 차이를 파악하고 득점 기술과 관련된 요인을 탐색함으로써 유도 전술 수립에 활용 할 수 있는 실무적 전략을 제시하고자 한다. 〔방법〕 2016년에서 2020년까지 총 5년간 국제유도연맹 주관 대회인 그랑프리, 그랜드슬램, 마스터즈, 세계선수권, 올림픽에 출전한 남녀 선수 전체를 대상으로 한판 또는 절반으로 연결된 50,828 득점 기술을 분석에 이용하였다. 세계유도선수들의 기술 유형에 따른 특성의 차이는 카이스퀘어 검정 $\left(X^{2}\right.$-test)을 실시하였으며, 기술 시간에 대한 집단 간 차이는 일원분산분석 (One-way ANOVA)을 보수적 사후검정법인 Scheffe 검정과 함께 사용하여 결과를 도출하였다. (결과〕 본 연구의 결과 남녀 모두 발 기술에 의한 기술 유형이 가장 많았고, 남자 선수는 손 기술이 여자 선수는 누르기와 발 기술의 비율이 상대적으로 높게 나타났다. 체급이 높아질수록 손 기술의 비율은 낮고, 누르기 비율은 높게 나타났으 며, 기술 유형의 빈도 또한 증가했다. 올림픽경기에서 굳히기 기술 비율이 다른 대회에 비해 높게 나타났으며 연도가 진행될수록 손 기술과 허리 기술의 비율이 높아졌고, 누르기는 줄어드는 양상을 보였다. 메치기 기술은 절반으로, 굳히기 기술은 한판으로 연결되는 비율이 상대적으로 높았으며, 준결승과 결승으로 갈수록 손 기술 과 발 기술의 비율이 상대적으로 높게 나타나는 양상을 보였다. 기술 시간에 대해서는 남자 선수의 기술 시간 이 평균 12 초가량 더 길게 나타났으며, 헤비급이 가장 낮게, 중량급이 가장 길게 나타났다. 아시아 대륙의 선 수들이 기술 시간이 가장 길게 나타났는데, 이는 체력이 우수하고 지구력이 좋으며 굳히기 기술이 강한 특성에 서 비롯되었다고 판단된다. 누르기와 손 기술에 의해 득점으로 이어지는 기술 시간이 가장 길게 나왔으며, 허 리 기술과, 조르기 기술 시간이 상대적으로 짧게 나타났다. 절반이 한판에 비해 평균 5 초 정도 더 짧게 나타났 으며, 중요한 경기일수록(예선4차전, 준결승, 결승) 기술 시간이 길어지는 양상을 보였다. 〔결론) 결론적으로 이 연구를 통해 세계유도선수들의 기술 유형과 시간에 대한 특성을 확인하였으며, 이를 바탕으로 유도 경기력 향상을 위해 우리나라 선수들을 포함한 세계 우수 선수들의 기술 유형을 심층적으로 분석하고 체계화 하는 것이 필요하다.

주요어: 유도, 엘리트 선수, 스포츠 경기 분석, 스포츠 빅데이터, 유도 기술 분석, 유도 기술 분류 